\title{
CONTRA LA VISIÓN FABRIL DE LA EDUCACIÓN: ¿UNIVERSIDADES CON FINES DE LUCRO?*
}

\author{
Arturo Fontaine \\ Centro de Estudios Públicos
}

\begin{abstract}
Resumen: En esta conferencia se tratan diversos temas que, de distintas maneras, abordan lo peculiar que es la educación universitaria, motivo por el que tiene un estatuto jurídico especial. Se critica la práctica chilena de que universidades sin fines de lucro, desde un punto de vista legal, de hecho sean empresas con fines de lucro; se hace un recuento de la experiencia de las universidades con fines de lucro en Estados Unidos; de las fuertes asimetrías de información que hay entre el alumno y la institución universitaria; se consideran las limitaciones que tienen las mediciones de la educación universitaria; se enfatiza el papel de la universidad en la formación de la persona, del ciudadano y del profesional y se argumenta en favor del financiamiento estatal y de la filantropía con beneficios tributarios, dados los bienes públicos que genera la formación universitaria. El autor se opone
\end{abstract}

Arturo Fontaine. Director del Centro de Estudios Públicos; profesor del Departamento de Filosofía de la Universidad de Chile y escritor. Su última novela es La vida doble (Tusquets).

* Versión revisada de la presentación (publicada en CIPER el 4 de agosto de 2012) en el foro "Propuestas para una nueva Superintendencia de Educación Superior" organizado por el Centro de alumnos de la Escuela de Derecho de la Universidad de Chile el 12 de julio de 2012, en el que participó junto a Fernando Atria y Esteban Serey. 
a lo que llama "la visión fabril de la educación", según la cual los "productos" de la universidad requieren "controles de calidad" y destaca la importancia de la formación como proceso.

Palabras clave: educación universitaria, educación con fines de lucro, educación sin fines de lucro.

\section{AGAINST AN INDUSTRIAL VIEW OF EDUCATION: NOT-FOR-PROFIT UNIVERSITIES?}

Abstract: The author addresses here several topics concerning the peculiar nature of the education that a university provides, which is the reason why these institutions have a special legal regulation. He objects the Chilean practice by which universities, legally not-for-profit institutions, are in fact for-profit institutions. An account is presented of what has been the experience of US forprofit universities, of the strong asymmetries of information between students and universities, and of the limitations inherent in the measurement of higher education. Special emphasis is given to the role of higher education in the development of students as human beings, citizens and professionals. It is argued in favor of allocating state funds to universities and tax benefits for philanthropy, in view of the "public goods" that a university produces. The author opposes to what he calls "an industrial view of education", emphasizing instead the importance of considering education as a process.

Keywords: higher education, not-for-profit universities, forprofit universities.

\section{1. ¿Hay universidades que lucran en Chile?<smiles>[CH]C(C)C[CH2]</smiles> \\ universidades privadas vuelven a tomar el} protagonismo en el mundo de los negocios" comienza diciendo el artículo "Universidades: un mercado bullente", publicado en Qué Pasa el 18 de junio del 2010. Luego alude a transacciones por "US\$70 millones por el $60 \%$ de la Universidad Santo Tomás", "US\$40 millones por la Uniacc" y "alrededor de US\$250 millones en la compra de las universidades Andrés Bello (2003), Las Américas (2006) y Viña del Mar (2009)". Afirma que "ex controladores de la Universidad Andrés 
Bello" que entraron a la propiedad de la San Sebastián "han invertido cerca de US\$ 100 millones". Más adelante señala: "La Ley Orgánica Constitucional de Enseñanza (LOCE) establece que las universidades privadas son entidades sin fines de lucro, pero aquí hay bemoles [...] son pocas las que admiten que parte de sus utilidades terminan en dividendos para los accionistas".

Se estima que "el mercado de las universidades privadas mueve entre US\$1.800 millones y US\$2.000 millones anuales" [...] la rentabilidad [...] alcanza "al $15 \%$ o al $18 \%$ ". Según un rector entrevistado: "el modelo de negocios [...] es similar al retail. Parte importante de 'las ventas' están asociadas a los créditos que los mismos alumnos y sus familias piden a los bancos $-\mathrm{o}$ al Estado - para financiar sus estudios. [...] Como las ues no pueden repartir dividendos, los dueños de estas entidades crean sociedades inmobiliarias, que son las que levantan los edificios en los cuales operan las casas de estudio. [...] Y a través del arriendo obtienen dinero de las fundaciones educacionales. Es una fórmula para poder extraer los recursos que se han acumulado". Un ex controlador asegura que "en algunos casos los centros de computación, los servicios de transporte y parte de las empresas externas - como los guardias - son propiedad de los dueños de la casa de estudios, quienes cobran por éstos a la universidad".

En una entrevista titulada "Cuarto mayor administrador de capital privado evalúa inversión en Chile”, publicada en El Mercurio, "Economía y Negocios", el 3 de junio del 2011, se preguntó a Henry Kravis - fundador y CEO de KKR - " ¿Ha analizado oportunidades de inversión en Chile?" "Efectivamente - contestó- Volveré. He quedado impresionado. Me junté con la gente del gobierno y Chile está en buen pie”. Y, luego, “¿Qué conversó con las autoridades?” Mr. Kravis responde: "Hablamos mucho sobre necesidades de infraestructura y de educación que Chile requiere. Nosotros tenemos tres universidades en Chile a través de Laurete Education (fondo que controla KKR), Andrés Bello, Universidad de las Américas y el instituto AIEP [...] Esa industria nos parece muy interesante".

Sin duda, hubo aquí un problema de traducción. O, quizás, si no había traductor fue un problema de acento. Sin duda, nuestras autoridades le explicaron a Mr. Kravis que en Chile, a diferencia de Estados Unidos, por ley las universidades no pueden ser negocios. Sin duda, Mr. Kravis no entendió bien. Pero Mr. Kravis lo que sí entiende 
- y muy bien- es qué es un negocio y qué no lo es. Es uno de los grandes de Wall Street. Y Mr. Kravis cree de buena fe que tiene en Chile un buen negocio, y lo dice. Lo que no le impide donar a universidades que realmente no tienen fines de lucro. Conoce perfectamente bien la diferencia. No hace mucho donó, por ejemplo, cien millones de dólares a Columbia University, donde estudió.

En una información divulgada por Reuters el 29 de marzo del 2012 se anuncia que "Laurate Education se prepara para una IPO" (initial public offering). Más adelante se lee que "los planes para un largamente anticipado IPO de Laureate llegan cuando en el mercado accionario de USA [...] las evaluaciones de compañías del mismo rubro han sido golpeadas debido a investigaciones de los reguladores, publicidad perjudicial y lento crecimiento. Laureate, sin embargo, tiene una fuerte exposición en mercados emergentes. La mitad de sus ingresos viene de México, Chile y Brasil, donde la educación postsecundaria está menos regulada, según una nota de Standard \& Poor's". Más adelante afirma que KKR \& Co. LP (KKR.N) pagó "US\$ 3.82 billones por Laureate". El consorcio que lidera KKR está integrado también por Citigroup Private Equity, S.A.C. Capital Management LLC, SPG Partners, Bregal Investments, Caisse de depot et placement du Québec, Sterling Capital, Southern Cross Capital, entre otros.

Si no estamos hablando aquí de negocios, ¿de qué estamos hablando?

$\mathrm{Y}$ a estas informaciones se podrían añadir las de CIPER y, por cierto, la investigación contenida en el libro El Negocio de las Universidades en Chile de María Olivia Mönckeberg, recientemente reeditado (2012).

\section{Las universidades tienen un estatuto jurídico particular}

La ley chilena que establece que las universidades son corporaciones sin fines de lucro viene de 1981 (Ley 18.962 y sus modificaciones, artículo 34). Esto significa que los excedentes que existieren, una vez cubiertos los costos, no pueden ser distribuidos como utilidades entre los socios o controladores de la institución. Por el contrario, cualquiera sea su origen (donaciones, rentabilidad por inversiones, matrículas, servicios, aportes del Estado, u otros) han 
de ser destinados a la prosecución de su finalidad propia. Si — por ejemplo, por la vía de una empresa suya que arrienda a la universidad los terrenos en los que funciona - un controlador lograra que una parte de los excedentes terminara en sus manos se habría transgredido el principio de la no distribución de excedentes. Si eso sucede, la prohibición de lucrar pasa a ser inoperante, es letra muerta. Estos resquicios son triangulaciones que dejan a los mismos a ambos lados del mesón. Utilizar máquinas legales para convertir las universidades en inversiones o negocios es contrario al espíritu de la ley y constituye una actividad antijurídica.

La norma prohíbe el lucro; no sólo el lucro excesivo o abusivo. (Para esto último no sería necesario un estatuto jurídico especial.)

Ello se establece anticipando un posible conflicto de interés entre los fines de la institución y los propios de los encargados de dicha corporación universitaria. Se trata de una norma prudencial. Como veremos ello tiene su lógica.

Como he escrito en otra oportunidad, “¿Puede una universidad estatal o una sin fines de lucro crear una empresa comercial que haga estudios (informes económicos, financieros, jurídicos, medioambientales, por ejemplo) remunerados por terceros y con ello complementen sus ingresos sus académicos y la universidad incremente los recursos con que cuenta para sus fines? Por cierto. ¿Puede una universidad de esa naturaleza permitir que sus docentes se agrupen y constituyan una sociedad comercial para prestar, por ejemplo, servicios médicos pagados por terceros? Por cierto. ¿Puede una universidad permitir que sus investigadores se asocien con una empresa comercial (un laboratorio, por ejemplo) y con la propia universidad para realizar determinadas investigaciones y, eventualmente, lucrar con la patente generada por la investigación de marras? Por cierto. En todos estos casos los universitarios involucrados están realizando actividades propias de un académico y allegando recursos para la universidad y/o mejorando sus ingresos por esa vía. Por cierto, pueden suscitarse conflictos de interés. Dependerá de cada universidad fijar los criterios que organicen y normen estas actividades que, prima facie, son no sólo perfectamente lícitas sino muchas veces convenientes para desarrollar la innovación y la investigación. No estoy seguro de que el Estado deba regular estas situaciones, pero tampoco lo excluyo de manera tajante. Es un asunto que merece un análisis 
pormenorizado" (http://ciperchile.cl del 6 de enero del 2012 y www. cepchile.cl).

Pero estas reflexiones no apuntan a lo anterior sino a situaciones que implican ingresos obtenidos por los controladores de la universidad - a su vez dueños de una empresa comercial - llevando a cabo actividades lucrativas no académicas y que celebran contratos con esa misma universidad. Son estas prácticas arteras las que violentan el espíritu de la ley y alimentan la desconfianza no sólo respecto del comportamiento de los empresarios en este rubro específico sino que más allá de él. Comienza así la deslegitimación de la empresa privada en otras áreas aunque en ellas marche bien. Son situaciones agraviantes que tienden a producir un efecto dominó. Nada se saca con cerrar los ojos. Esto mancha al empresariado. Sobre todo ante la juventud. Ello tendrá consecuencias. De hecho, las están teniendo ya.

Nunca ha habido en Chile universidades con fines de lucro. Hasta 1981 las universidades se creaban por ley y todas las privadas fundadas de este modo - la PUC, la Universidad de Concepción, la Universidad Austral, la Federico Santa María - fueron instituciones sin fines de lucro. Uno podría afirmar que en Chile nunca se pensó permitir universidades con fines de lucro. Cuando se reformó la LOCE, durante el gobierno de Michelle Bachelet, esa norma no se cambió.

Los títulos universitarios son reconocidos por el Estado y, por lo tanto, estas prácticas atentan contra la fe pública. Estos títulos sólo pueden ser concedidos por las universidades. Las universidades tienen un régimen legal especial: no pagan impuestos de primera categoría, no pagan IVA por sus servicios, no pagan la contribución de bienes raíces y pueden recibir donaciones que las empresas descuentan, en parte, de su renta imponible... Las empresas inmobiliarias que arriendan a instituciones educacionales no pagan el impuesto a los bienes raíces. Las universidades pueden obtener recursos del Estado para la investigación vía los concursos de Conycit y sus alumnos vulnerables — según la última propuesta del Gobierno, en principio, hasta un $60 \%$ del totalfinanciarían sus estudios con becas y préstamos blandos ( $2 \%$ de interés) avalados por el Estado y que, según dicha propuesta, se devolverían en cuotas relativas al ingreso del titulado y en cualquier caso a los quince años la deuda se extinguiría. Las universidades están sometidas a un sistema de acreditación que depende del Estado. 


\section{3. ¿Tiene algo peculiar la educación universitaria?}

Pregunta: ¿cuál es el fundamento de este régimen jurídico de excepción? El asunto obliga a reflexionar acerca de la naturaleza de la educación.

¿Por qué financia el Estado la construcción de viviendas sociales y permite que su construcción sea realizada por empresas privadas comerciales y no sucede lo mismo en las universidades? ¿No hay aquí una contradicción? ¿No hay aquí un viejo prejuicio y nada más? Lo que resulta en ciertos mercados - si son competitivos - como el de la ropa, los jabones o los preuniversitarios, por ejemplo, debe resultar también en el campo universitario. Mal que mal el ser humano es el mismo. Los incentivos que funcionan aquí deben funcionar allá. Se razona así por analogía.

Los preuniversitarios y las escuelas de idiomas, por ejemplo, son instituciones educacionales, pero no están sometidos a un estatuto jurídico específico y tienen fines de lucro. Funcionan razonablemente bien.

Lo que caracteriza a una universidad es el carácter multidimensional de su educación. La formación tiene una parte privada y una parte pública. El estudiante que se gradúa en derecho en esta facultad, debiera por un lado ser capaz de ganarse la vida como abogado. Por otro, ha de haber sido educado como persona y como ciudadano, y como ciudadano que tendrá un peso especial por su educación. "La educación superior", escribe Martha Nussbaum, "prepara a los estudiantes [...] para una carrera, pero también para ser ciudadanos y para vivir" (2010, p. 149). La conducta profesional interesa no sólo a él y a sus clientes sino que al país. El clima de juridicidad o anti-juridicidad imperante, por ejemplo, depende en importante medida de cómo se comportan los abogados, qué censuran, qué toleran y qué celebran.

Ese joven abogado no sólo será un profesional y un ciudadano sino que una persona que toma decisiones, que ama, tiene hijos, amigos y amigas, tiempo libre, aficiones, y que tendrá logros y decepciones, alegrías y sufrimientos. La universidad debe acompañar, creo, al joven en ese periodo crucial en el que va pasando de su última adolescencia hasta el preludio de sus días como joven adulto. Estos años universitarios son los de las grandes preguntas, las que apuntan al sentido de lo que hacemos y queremos de nuestras vidas. 
He hecho clases de filosofía en la Escuela de Ingeniería Civil de la Universidad de Chile y he visto cómo, pese a que algunos alumnos llegan a la clase exhaustos y con irrefrenables ganas y necesidad, incluso, de dormir, surgen allí inquietudes e interrogantes verdaderamente filosóficas que se plantean con inteligencia y naturalidad. Y he comprobado con qué genuina curiosidad intelectual pueden estudiar estas materias.

"Nunca he encontrado", escribe Andrew Delbanco, "una mejor formulación - 'muéstrame cómo pensar y cómo elegir'- de lo que una universidad debe tratar de ser: una ayuda para la reflexión, un lugar y un proceso mediante el cual la gente joven hace un balance de sus talentos y pasiones y empieza a ordenar su vida de una manera que es verdadera para ellos y responsable respecto de los demás" (2012, loc. 318). Es un grave error - diría que a veces es la marca de un prejuicio clasistapensar que una educación así sólo es para los privilegiados. Al contrario. Nuestra tarea es darles a grupos amplios de estudiantes este tipo de educación y no resignarnos a que sea la prerrogativa de unos pocos afortunados.

La instrucción que imparte un preuniversitario o una escuela de idiomas, en cambio, es reducible a un conjunto de conocimientos que pueden identificarse y medirse con bastante precisión. Un preuniversitario no se ocupa de formar a una persona, a un ciudadano. La universidad sí.

Una institución educacional con fines de lucro funciona bien cuando puede medir sus resultados. Porque logradas las metas propuestas, el dueño tiene derecho, entonces, al excedente. Es lo que ocurre en una escuela de idiomas. El alumno puede evaluar razonablemente bien los resultados de la instrucción. También podría hacerlo una agencia del Estado. Es lo que ocurre cuando una empresa constructora hace casas con subsidios estatales. Las especificaciones permiten a los funcionarios del Estado verificar con suficiente precisión si la casa cumple o no con lo que se pedía.

En los procesos educacionales complejos eso no es posible. Por ejemplo, en el proceso educacional más importante: la paternidad y la maternidad. No se puede reducir lo que debe hacer un padre a un conjunto de variables que podríamos medir y evaluar. Hay algo que escapa a todo indicador. Por eso no tendría sentido contratar a un padre. (Éste es el tipo de cuestión que explora Michael Sandel en su último libro 
[2012]). No es que no se pueda. Podríamos contratar a un padre y fijar una pluralidad de variables y sus ponderaciones, en función de las cuales se evaluaría su rendimiento. Podría suceder que ese padre lograra un excelente rendimiento en todos los indicadores, superior incluso al de una muestra representativa de los padres normales. Y sin embargo..., lo que quiero decir es que un padre contratado para serlo no es un padre. Eso, lo que hace un padre, no se hace por dinero. No es cuestión de "resultados". Si una persona llegara a ser para un niño, para un adolescente, un verdadero padre o madre y descubriera después que ese padre, que esa madre lo hizo por dinero, creo que ese joven sentiría que ha sido engañado.

Quiero decir que - aunque ciertamente el caso no es tan extremo como el anterior - para el educador, en los momentos en que es propiamente un educador, educar es una extensión de la paternidad o de la maternidad. Tal vez por eso la cuestión del lucro en la educación suscite tantas aprensiones y preguntas hasta hoy y desde tan antiguo. Ya Sócrates ironizó a los sofistas por supeditar la educación al lucro y vender saberes que no tenían, en otras palabras, por "pasar gato por liebre". El sofista, según Platón, es criticado por ser un "cazador de jóvenes ricos", un "mercader (emporos) de los conocimientos del alma" y un "mercachifle (kapelos) de estos mismos conocimientos" (El Sofista, 231d). Xenofonte los ve como "meretrices del saber" (Memorabilia, I. VI.13 y ss.). Haya sido justa o injusta la acusación, nos dice algo acerca del concepto de educación. Me gustaría invitarlos a reflexionar y discutir sobre esto.

Por cierto, en la universidad se puede y debe evaluar el conocimiento de los alumnos en determinadas materias. Pero siempre importantes dimensiones quedan fuera y - asunto delicado- se afecta el modo en que se educa. Si la prueba controla material aprendido de memoria, el alumno va a memorizar. Si se trata de trabajos escritos y razonados, el alumno se ejercitará en ello. La importancia y multiplicación de pruebas de opción múltiple hace que la educación devenga un adiestramiento para ese tipo de pruebas. La medición altera lo medido. No es neutra. Todo profesor lo sabe.

Analizando los efectos negativos del programa No Child Left Behind del ex presidente George Bush, Diane Ravitch (que fue entonces subsecretaria de Educación y es hoy una crítica aguda de ese programa) ha escrito: "Las pruebas que se usan $[. .$.$] fueron diseñadas con propó-$ 
sitos específicos: medir si los niños pueden leer y hacer matemáticas, e incluso en esto deben ser usadas con atención a sus limitaciones y variabilidad. No fueron diseñadas para capturar las dimensiones más importantes de la educación, para lo cual no tenemos mediciones" (2010, p. 166). Estas pruebas, según el programa No Child Left Behind, tienen consecuencias en el sueldo de los profesores y permiten cerrar escuelas. El ejemplo de Finlandia muestra que hay maneras más adecuadas de mejorar la educación. "Cuando definimos", dice Diane Ravitch, "lo que importa en educación sólo en función de lo que podemos medir, estamos en serios problemas" (Ravitch, 2010). Sabemos bien a qué se refiere: en Chile se empieza hablando de la importancia de la educación y en un dos por tres, como si fuera una ecuación, estamos hablando del SIMCE... Lo que ella dice para los colegios vale igualmente para la universidad.

Por supuesto esta idea, de que lo no medible, lo no cuantificable, sea lo principal de la educación encuentra hoy formidables resistencias. Y hay algo que decir a favor de esas resistencias. Detrás de la búsqueda de mediciones hay una voluntad de mejorar la educación, de presionar al profesor flojo, de premiar al diligente. $\mathrm{Y}$ a veces la falta de medición excusa la indolencia. En ciertas situaciones, el empleo de pruebas de opción múltiple bien diseñadas es conveniente, incluso indispensable. Con todo, se ha ido imponiendo en distintas partes del mundo algo que va más allá: una visión fabril de la educación. Sus productos, se piensa, deben ser sometidos a controles de calidad tal como los productos de una fábrica. Y para eso están las pruebas estandarizadas y otros indicadores. El predominio de esta mentalidad hace que lo que no se mide se deje de lado.

En el trasfondo presiento una ruda metafísica positivista. Sólo existe lo que se puede medir y calcular. El atractivo es la posibilidad de transformación. Lo que mido es, como creo que intuyó Heidegger, lo que puedo tratar como material que moldeará mi voluntad. Es decir, lo que puedo medir es lo que puedo dominar. Los gobiernos tienen una tendencia natural a preferir estas mediciones porque ellas son mecanismos de control. A través de ellas extienden su dominio. Si el dinero del Estado fluye a lo medible, fluye a lo controlable. Por eso lo que está en juego en estas discusiones tiene que ver con la libertad de la universidad. Estos espacios de lo no medible son los espacios de nuestra verdadera libertad. 
¿Cómo medir el efecto de un foro como éste, organizado por estudiantes para discutir el lucro en la educación? Y, sin embargo, es a través de actividades como ésta que se va construyendo lo que Habermas llama el "espacio público", es decir, el lugar de la conversación y deliberación de temas cívicos. Y es ese espacio público lo que nutre la democracia.

En la educación, como ha señalado Fernando Atria (2012, p. 71 y ss.), importa a menudo más el proceso que el producto. ¿Cómo evaluar si hemos aprendido a disentir? A juicio de Nussbaum "el pensamiento socrático es importante en cualquier democracia [...] La idea de que uno debe hacerse responsable de su propio razonamiento, e intercambiar ideas con otros en una atmósfera de mutuo respeto por la razón, es esencial para la resolución pacífica de las diferencias" (Nussbaum, 2010). Sin embargo, "esta habilidad para pensar y argumentar por sí mismo le parece a mucha gente algo descartable si lo que queremos son resultados vendibles de naturaleza cuantificable. Más aún, es difícil medir la habilidad socrática a través de pruebas estandarizadas. Sólo una matizada evaluación cualitativa en el intercambio en la clase y los trabajos escritos de los alumnos podrían decirnos hasta qué punto los estudiantes han aprendido las destrezas de la argumentación crítica" (Nussbaum, 2010, p. 48).

Según esta filósofa, "el cultivo de la imaginación está estrechamente ligado a la capacidad socrática para criticar las tradiciones muertas e inadecuadas, y provee un cimiento esencial para esta actividad crítica. Difícilmente se puede tratar a la posición intelectual de otra persona con respeto si uno al menos no intenta ver qué visión de mundo y en general qué experiencias la generaron" (Nussbaum, 2010, pp. 109-110). Y para ello Nussbaum cree que la clave son las artes y la literatura. Es decir, sumergirse en el mundo de la ficción es parte de la formación de la persona en la universidad y también del ciudadano de una democracia. Porque la literatura y las artes ayudan a imaginar lo que son las demás personas, lo que es vivir desde sus vidas, y muestran la diversidad y multiplicidad que se esconde en el interior de cada ser humano. El cultivo de la imaginación nos acerca a la aventura que es descubrir y crear en cualquier actividad humana.

Los gobiernos, en general, tienen poco interés en desarrollar las humanidades y las artes en la universidad. Incluso las autoridades universitarias, a veces, prefieren escuelas fuertemente profesionalizantes en las que los estudiantes puedan ser domesticados por aprendizajes ago- 
biantes que refrenan, por importunas, las preguntas e indagaciones más fundamentales que se plantean típicamente a esa edad. Y ésas son, por cierto, las grandes interrogantes humanas - muchas de ellas de tonalidad ética - que debieran constituir el horizonte de la universidad. Pero, claro, el lenguaje tecnocratizante trata de esquivarlas. Son "cuestiones inagarrables", piensan, inmersos como están en una visión fabril de la universidad y de la vida. No obstante, la actual presidenta de Harvard University, Drew Gilpin Faust, en un artículo publicado en el New York Times el 1 de septiembre del 2009 afirmó que "las universidades intentan ser productoras no sólo del conocimiento sino que (a menudo algo inconveniente) de la duda. Son lugares creativos y desordenados, casas de una polifonía de voces". Y más adelante: "Los seres humanos necesitan sentido, comprensión y perspectiva, así como también empleos". Para la presidenta de Harvard "las universidades son para bastante más que para la utilidad medible [...]. Ni las cuestiones permanentes de la indagación humanística ni el sinuoso camino de la investigación científica que conducen a la postre a la innovación y al descubrimiento pueden calzar con pulcritud en un presupuesto y una agenda predecibles" (Faust, 2009).

Un enfoque así choca con esa mentalidad fabril que predomina hoy cuando se habla de educación. Y, sin embargo, una universidad así concebida lidera en el mundo virtualmente todos los rankings que usan los interesados en las mediciones, atrae a los jóvenes más capaces, sus titulados consiguen excelentes trabajos — por cierto también en Wall Street - y es a la que los empresarios le quieren donar más. "There are more things in heaven an earth, Horatio,/ Than are dreamt of in your philosophy". (Hay más cosas en el cielo y en la tierra, Horacio,/ Que las que se sueñan en tu filosofía).

Estas consideraciones dan una idea de las peculiaridades de la universidad y acerca de por qué requiere un estatuto jurídico especial. A diferencia, entonces, de lo que ocurre con un preuniversitario o una escuela de idiomas - y desde luego con una empresa constructora que hace casas subsidiadas por el Estado-, lo más importante de la educación propiamente universitaria no se puede medir de manera objetiva. Se puede evaluar sólo hasta cierto punto, y de modo cualitativo, imperfecto y parcial. Las mediciones de actividades universitarias susceptibles de evaluación cuantitativa - en cuanto tengan consecuenciasmodifican la educación y tienden a concentrarla en lo que se mide. Se 
corre entonces el riesgo de reducir, tergiversar y degradar el sentido mismo de la educación universitaria. Por lo tanto, estas mediciones - aunque útiles y necesarias - han de ser empleadas con mucho tino y parquedad.

\section{La universidad provee bienes individuales y públicos}

La educación universitaria ha sido financiada desde hace muchos siglos tanto por benefactores particulares o mecenas como por el Estado. En la antigua Roma, por ejemplo, como cuenta el historiador Henri-Irénée Marrou, los emperadores Vespasiano y Adriano instituyeron cátedras en Roma y en Atenas. Pero, por ejemplo, Plinio el Joven, un mecenas importante, instituyó una cátedra con su propio dinero. La Universidad de Constantinopla, fundada por Teodosio II el año 425, se financiaba con recursos del Estado. Pero, por otra parte, en Roma la educación técnica, principalmente la instrucción de los escribientes, era organizada de manera comercial (Henri-Irenée Marrou, 1948, pp. 112114, 118, y124). La situación no ha cambiado demasiado, pareciera. ¿Cuál es la lógica que lo explica?

La educación propiamente universitaria promueve, a la vez, bienes individuales (el joven se prepara para ejercer una profesión y se cultiva como persona) y públicos (se cultiva como ciudadano). Además la universidad que investiga es un vivero de ideas y, eventualmente, de hallazgos y descubrimientos. En otras palabras, la universidad produce bienes públicos. Por eso tiene derecho al financiamiento del Estado.

Si una universidad forma buenos ciudadanos ello tenderá a mejorar las decisiones políticas y las instituciones de la sociedad. Si estudios y seminarios suyos abordan temas políticos, económicos y sociales, si la universidad se constituye en "un espacio público", en el sentido de Habermas (1962), si aporta a la construcción de lo que Robert Putnam (1993) ha llamado el "capital social", produce, en el cumplimiento de sus tareas más propias y clásicas, un bien público de gran valor para la democracia. Economistas como Acemoglu y Robinson, por ejemplo, sostienen en un libro reciente que lo que explica el desarrollo de ciertos países y el retraso de otros es, simplemente, su institucionalidad: "Los países difieren en su éxito económico por sus diferentes instituciones, ya que sus reglas influencian cómo funciona la economía, y los incentivos que motivan a la gente" (2012, p. 73). 
Típicamente, como sabemos, los bienes públicos o son financiados por el Estado o por benefactores. O la cátedra la financia el emperador Adriano o el mecenas Plinio el Joven. O, por cierto, una combinación de ambos como ocurría en Roma y ocurre hoy con frecuencia en los Estados Unidos

Un alumno al considerar su propio beneficio tiene dificultades para averiguar si la enseñanza de neurología de la universidad A o B es mejor o peor. Hay una enorme asimetría de información, lo cual lo hace más vulnerable al engaño que cuando está, digamos, comprando calcetines. Es más fácil para una universidad "pasar gato por liebre" que para un fabricante de calcetines.

¿Sin embargo, qué sucede, por ejemplo, en el caso de los fármacos psicotrópicos? El paciente no está en condiciones de evaluarlos. Pero una agencia estatal certifica su calidad y su administración queda en manos de los médicos. ¿No puede hacerse lo mismo con las universidades? ¿No puede el Estado fijar metas y controlar su cumplimiento? Sólo hasta cierto punto. Los sistemas de acreditación estatal, los rankings, los índices de selectividad, la publicidad de los ingresos de los graduados, las publicaciones, y otras, aunque útiles, son meras aproximaciones. Los criterios son laxos, inexactos y de menor amplitud, es decir, lo que se evalúa es incompleto y reductor. Para lo más importante, simplemente, no disponemos de medidas.

Si los calcetines que compró el joven se rompen al poco andar, la próxima vez ensayará otra marca. En cambio el tiempo que toman los estudios universitarios es mayor y su oportunidad es más limitada. El titulado, a veces, sólo cuando consiga trabajo podrá empezar a evaluar cómo fueron sus estudios. En ese momento ya es de inmenso costo volver a empezar. Es decir, hay cierta irreversibilidad. "Dado que el tiempo requerido por el consumidor para descubrir y reparar los inconvenientes de una educación pobre o fraudulenta podría medirse en años, el consumidor corre un serio riesgo de ser explotado" (Pusser, 2006, loc. 534). Y dos personas, una con una buena educación y otra con una mala tienden a tener productividades distintas por el resto de sus vidas.

Todo lo anterior indica que la educación tiene particularidades que es conveniente considerar a la hora de diseñar políticas universitarias. Aunque para muchos sea más atractivo suponer que hay un solo modelo explicativo. Lo contrario es molesto porque le quita simplicidad a la teoría. (Pero ya los bancos y el sistema financiero requieren de minuciosas 
regulaciones especiales que le quitan simplicidad al esquema general). No obstante, algunas mentalidades se apegan como lapas a la rocas cuando encuentran una teoría que lo explica todo. Ante la diversidad de la experiencia humana se resisten y prefieren quedarse adheridos a su roca tratando de evitar la angustia de la incertidumbre. Pero en este caso, la analogía con las viviendas sociales construidas por empresas constructoras, con los preuniversitarios y escuelas de idiomas pasa por alto lo propio de la educación. Tal razonamiento por analogía es cómodo, pero simplista.

Dado el peso de las asimetrías señaladas, en principio, el estudiante está más protegido en una institución sin fines de lucro. Porque la cláusula de no distribución de excedentes propia de las instituciones sin fines de lucro, afirma Brian Pusser, "protege al consumidor de las potenciales asimetrías de información y otros riesgos morales al remover la posibilidad de que el afán de lucro incentive a los productores a explotar a sus consumidores" (2006, loc. 534). Es una norma prudencial específica.

\section{5. ¿Qué ha sucedido, entre tanto, en Estados Unidos?}

Como se sabe, allí conviven universidades estatales, privadas sin fines de lucro y privadas con fines de lucro. La ley lo permite. Las con fines de lucro no gozan, por cierto, de exenciones tributarias ni de beneficios para los que les donan. Funcionan como empresas comerciales. Con todo, se someten a ciertas reglas especiales (acreditación, por ejemplo) y reciben alumnos con becas y créditos subsidiados por el Estado.

University of Phoenix, del Apollo Group, con más de 250 mil estudiantes en Estados Unidos, es la más exitosa de las con fines de lucro. El 69\% de sus alumnos ha trabajado a tiempo completo nueve o más años. Más de la mitad son mujeres. Son personas de bajos ingresos y con créditos o becas del gobierno. No hay selección para el ingreso. El alumno comienza en cualquier momento del año y planifica con un tutor todos los cursos que conducirán al título o certificado que busca. Los primeros cursos comenzarán para él/ella a la semana siguiente. Es decir, no hay semestres o trimestres comunes. El alumno toma dos cursos a la vez, generalmente vespertinos, que duran cinco o seis semanas. El programa está centralizado y no depende del profesor. Todo el material del curso llega online y no hay bibliotecas, casinos ni facilidades deportivas. Los campus son de fácil acceso y tienen amplios estaciona- 
mientos. Casi la mitad de las carreras que se ofrecen en pregrado son de negocios o administración. No hay medicina. Tampoco derecho. Es, en verdad, un centro de capacitación y reciclaje laboral.

Si uno hubiera comprado US $\$ 10$ mil dólares en acciones de Apollo en 1994, diez años después habrían valido más de un millón de dólares (US\$1.034.743) afirma el economista David Breneman (2006, loc. 59). La compañía ha sido bien rentable.

Según Breneman, las universidades "con fines de lucro han detectado con éxito nichos de mercado en áreas profesionales y técnicas específicas, pero estos mercados tienen límites naturales [...] el mayor potencial para estas instituciones ha de estar en el exterior, en países en desarrollo" (2006, p. loc. 1290).

Se discute bastante acerca de estos colleges y universidades, en términos de su costo e impacto en los ingresos futuros vis- à-vis instituciones similares.

En Estados Unidos hay muchas instituciones con fines de lucro que no reciben alumnos con financiamiento estatal. Una investigación reciente de Riegg Cellini y Goldin $(2012$, p. 25) concluye que si se comparan los costos de la matrícula se comprueba que en el subsector con fines de lucro y apoyo financiero del Estado el cobro es "aproximadamente un $75 \%$ más alto" que en instituciones similares con fines de lucro y sin apoyo estatal. Otro estudio, de Kevin Lang y Russell Weinstein (2012, p. 25), después de llamar a la cautela por las limitaciones de la investigación, afirma que "nuestros resultados sugieren con fuerza que, incluso después de controlar por una amplia gama de variables relativas al medio socioeconómico, los alumnos de las instituciones con fines de lucro no se benefician más y a menudo se benefician menos de su educación que alumnos aparentemente similares de instituciones sin fines de lucro y públicas". Otro estudio, de David J. Deming, Claudia Goldin y Lawrence F. Katz (2012, p. 16), concluye que la gran proporción de becas y créditos estudiantiles del Estado que capturan muchas de estas universidades "les ha permitido proveer destrezas a poblaciones desaventajadas. [...] Pero sus estudiantes [...] terminan más endeudados, experimentan mayor desempleo después de dejar la escuela, y, cuando lo consiguen, obtienen menores ingresos [...] que estudiantes similares de instituciones públicas y de instituciones sin fines de lucro. No sorprende que los estudiantes de instituciones con fines de lucro tengan mayores porcentajes de morosidad en sus deudas y estén menos 
satisfechos con su experiencia [...]". Por tanto, incluso la rentabilidad comparada de los colleges con fines de lucro para sus graduados parece estar en entredicho.

El jurista Richard Posner, un partidario de las universidades con fines de lucro, cree, sin embargo, que el fraude es "más probable" en estas instituciones que en las sin fines de lucro: "Primero, porque los consumidores servidos por estas instituciones son menos sofisticados que los consumidores (los estudiantes y sus familias) de los servicios educacionales que proveen las instituciones establecidas. Segundo, las instituciones establecidas tienen más capital en reputación que una empresa nueva; por tanto, el fraude y otras formas de mal comportamiento son más costosas para ellas y hacen mayores esfuerzos para prevenirlos" (2006).

El año 2004 el Ministerio de Educación de Estados Unidos informó que Phoenix University pagaba promotores en función del número de alumnos reclutados, lo que viola una norma de elegibilidad para recibir estudiantes con créditos y becas gubernamentales. En general, según Breneman "la tentación de explotar las diferencias de información disponible para el estudiante potencial y el oferente, y la naturaleza del servicio provisto, indican que la producción con fines de lucro y la venta de servicios educacionales está repleta de oportunidades para un comportamiento menos que ético, en particular cuando un tercero (el gobierno federal) está pagando gran parte del servicio" (2006, loc. 1290). En buen romance, en este rubro es muy fácil "pasar gato por liebre". A partir de entonces se ha producido en Estados Unidos una avalancha de denuncias e investigaciones debidas a prácticas ilegales y abusivas en universidades con fines de lucro.

El conocido hedge fund manager de Wall Street Steve Eisman -quien además dio su testimonio ante el Senado de los Estados Unidos (24/6/2010) - afirmó que las universidades con fines de lucro "son socialmente tan destructivas como la industria hipotecaria sub-prime" (2010). Analizando sus argumentos y, en general, la situación creada hasta entonces en los Estados Unidos, Richard Posner ha concluido que "es probable que al hacer un balance los costos de las universidades con fines de lucro excedan sus beneficios" (2010). Según The Economist (22 de julio del 2010), el sistema ha estado funcionando así: "Los clientes llegan a los colleges con fines de lucro por millones. Con ellos llegan billones de dólares de becas y préstamos federales, que se 
derraman en los cofres de las compañías. Los subsidios estatales pueden proveer hasta el 90\% del ingreso; el gobierno asume los riesgos del no pago de las deudas. Este modelo de negocios le ha servido bastante a las firmas. Su efecto en los estudiantes y en los contribuyentes no es tan claro [...]. De las investigaciones realizadas en la educación post-secundaria por el Ministerio de Educación el $70 \%$ se refieren a universidades con fines de lucro [...]. El año 2009 Apollo Group aceptó pagar una multa de US\$78,5 millones". Bloomberg realizó una serie de investigaciones periodísticas según las cuales las universidades con fines de lucro se han transformado en una industria que mueve "30 billones de dólares al año a costa de los contribuyentes y apuntando a poblaciones vulnerables [...] con falsas promesas de bajos costos, ayuda académica online y puestos lucrativos tras la graduación. Mientras la ayuda federal a estas universidades, de propiedad de corporaciones prominentes como Goldman Sachs y Washington Post Co., ha aumentado por seis en la década y sus ejecutivos han obtenido dos billones de dólares en pagos y ventas de acciones, la mayoría de los estudiantes de las universidades con fines de lucro desertan y no pueden pagar sus deudas" (véase topics.bloomberg.com/bloomberg-investigation: forprofit-colleges/).

Hoy en día hay aproximadamente 30 fiscales generales (attorney generals) investigando denuncias de fraudes e ilegalidades de universidades con fines de lucro. Los últimos escándalos se refieren a engañifas destinadas a atraer a los soldados que vuelven de Afganistán e Iraq. La situación ha afectado la matrícula y el valor accionario de las respectivas compañías. El gobierno estadounidense ha intentado elevar las exigencias para que las instituciones puedan recibir alumnos con becas o créditos subsidiados. ¿Será suficiente? La batalla se ha trasladado a los tribunales.

\section{Finalmente, ¿alguna lección para Chile?}

Nuestro sistema hace que los incentivos para explotar las asimetrías de información sean mayores que si las universidades con fines de lucro fueran legales. Los controladores de las universidades pueden gozar a la vez de las ventajas de las universidades sin fines de lucro y de las de las empresas comerciales. 
Si las universidades con y sin fines de lucro se confunden, ¿no se daña a las sin fines de lucro genuinas? ¿A la hora de donar no debieran ser menos generosos sus ex alumnos si ven que la universidad de al lado recurre a inversionistas que aportan recursos a cambio de una rentabilidad y no necesita mendigar donaciones? ¿Para qué donar a una institución que podría ganarse ese dinero como cualquier empresa? ¿Quién le quiere donar a Citibank? ¿No tiene ventajas la universidad que, además de los beneficios tributarios de las sin fines de lucro, puede acudir a los inversionistas del mercado de capitales? ¿No pasan a ser vistas las instituciones sin fines de lucro como meras fachadas de empresas comerciales? ¿No horada eso la confianza en las instituciones sin fines de lucro $\mathrm{y}$, en particular, en las universidades?

Las malas prácticas establecidas socavan las bases que permiten la creación de una verdadera cultura de la filantropía en el campo universitario, algo que - como salta a la vista - el país necesita con urgencia. En esto debiéramos poner hoy especial énfasis. El empresariado, en mi opinión, debiera colaborar resuelta y generosamente con las buenas universidades públicas y privadas sin fines de lucro —en ellas se está urdiendo el futuro de Chile - y mantenerse a distancia de cuanto huela a negocio camuflado. Las prácticas y argucias en uso profundizan la brecha entre los ciudadanos corrientes y los que tienen poder minando la legitimidad de nuestras instituciones.

Es muy positivo, como se repite tanto, que seis de cada diez estudiantes sean de primera generación en la universidad. Sabemos que las universidades que la Comisión Investigadora de la Educación Superior de la Cámara de Diputados presume que de hecho tienen fines de lucro, han jugado un papel decisivo en esta vertiginosa expansión. Por ejemplo, las madres de más del 40 por ciento de los titulados de la Universidad de las Américas no tuvieron educación superior. En el caso de la Universidad Santo Tomás esa cifra llega al 60 por ciento.

Sabemos que el crédito blando y con aval del Estado ha potenciado este proceso. En efecto, desde que en el 2006 se creó el CAE (crédito con aval del Estado) para las universidades no tradicionales el número de sedes pasó de 2.030 en el 2005 a 3.107 en el 2011, un aumento de $53 \%$ en seis años (datos del Ministerio de Educación).

Pero los estudios del economista Sergio Urzúa indican que, desde el punto de vista de la rentabilidad de la educación universitaria, 
cerca del 40\% de los titulados chilenos salen para atrás (Urzúa, 2012). El sistema no da para más y requiere cambios profundos.

La experiencia de los Estados Unidos - y de nuestro paísrevela que es difícil y costoso regular y vigilar a las universidades con fines de lucro. Posiblemente Estados Unidos todavía no haya encontrado un buen sistema para hacerlo y la judicialización de los conflictos continúe.

Una universidad constituida como negocio debiera tender a explotar economías de escala y ofrecer una enseñanza estandarizada. Más que una institución de formación personal y ciudadana, y de investigación, será una institución de instrucción. Se centrará más en el alumno, entendido como consumidor. Más que motivar nuevas inquietudes se interesará en las que ya existen. La universidad se ocupará más de satisfacer las preferencias del estudiante que de cuestionarlas, más de ofrecerle lo que escoge que de enseñarle "cómo pensar y cómo escoger". Le convendrá, quizás, contratar algunos profesores estrella que ayuden a darle credibilidad y desarrollar, tal vez, algunas líneas de investigación que le permitan proyectar una imagen de universidad propiamente tal. Una agencia estatal puede fijar indicadores objetivos que perrmitan evaluar con bastante precisión la calidad de este tipo de intrucción y una universidad de esta naturaleza, tal como una escuela de idiomas, puede exhibir en cuanto a esos resultados, por cierto, muchísimo éxito. Ése no es el punto.

Por supuesto, caben posibilidades intermedias. Por ejemplo, que la búsqueda del lucro coexista con un afán ideológico, educacional o religioso, de tal modo que los dueños sacrifiquen una parte de sus ganancias en pos de esos otros objetivos. Pero salvo excepciones - y una golondrina no hace el verano- estos casos híbridos durarán mientras tengan el control los fundadores. Al pasar a la segunda generación lo probable es que deban elegir entre el modelo de una universidad sin fines de lucro o el de una universidad de verdad dedicada al lucro. Es lo que tiende a ocurrir con los colegios particulares pagados que en Chile no han estado prohibidos. Es frecuente que el maestro fundador lo organice como una entidad con fines de lucro - a menudo porque es más sencillo legalmente y su gobierno tiene menores costos de transacción que organizar una fundación sin fines del lucro$y$, no obstante, se comporte como lo haría el rector de un colegio sin fines del lucro. Esta fórmula híbrida difícilmente podrá trasladarse a 
sus herederos. Hay excepciones, claro. Pero a la larga, o se organizan como instituciones sin fines de lucro, o pasan a ser administrados como empresas lucrativas, o desaparecen. Tarde o temprano hay que abordar el paso de una autoridad carismática a una de tipo institucional. Es la ventaja que tienen las congregaciones religiosas: la institución está ahí desde el comienzo. Si uno observa los colegios independientes ingleses se encuentra con lo mismo: los más prestigiados de ellos están en manos de instituciones sin fines de lucro o de congregaciones.

Las universidades con fines de lucro tienden a parecerse a las escuelas de idiomas. Son instituciones más de adiestramiento e instrucción que universidades en sentido propio. $\mathrm{Su}$ aporte a la generación de bienes públicos, de existir, tenderá a ser muy magro.

Con todo, si queremos honrar el principio de la libertad de enseñanza y permitirlas por ley debieran organizarse como empresas comerciales, perder los privilegios de las sin fines de lucro y quedar sometidas a un severísimo estatuto especial diseñado con esmero. (Por ejemplo, quizás debieran estar obligadas a dar a conocer su carácter de universidades con fines de lucro en su propaganda). Sabemos por qué es necesario actuar con cautela y extremar la vigilancia, labor ardua y costosa. En cualquier caso, la tergiversación del espíritu de la ley que hemos vivido hace que hoy en Chile esto no tenga viabilidad política alguna.

A menudo se sobrestima la capacidad fiscalizadora del Estado y se subestima la astucia del mercader de la educación que conoce su negocio mejor que el funcionario que lo vigila. Ocurre en el proyecto de ley que crea una Superintendencia de Educación Superior presentado por el gobierno actual (Boletín No 8041-04). Aunque la intención haya sido otra, salvo que se le introduzcan cambios sustanciales, de aprobarse legitimará el statu quo.

El proyecto, como señalé el 3 enero pasado ante la Comisión de Educación del Senado, permite "que sociedades relacionadas con los controladores de la corporación sin fines de lucro, lucren a través de contratos celebrados [...] con la universidad, siempre y cuando se cumplan algunas condiciones". "La primera, de fondo, es que el precio sea el de mercado (Artículo 66 C). El fundamento es que si, por ejemplo, el arriendo de un bien raíz de propiedad de los controladores de la universidad, es arrendado por la universidad y el canon es el de mercado, es indiferente para la universidad quienes son los dueños del bien raíz”. 
"La segunda, de procedimiento, es que dicha transacción con sociedades relacionadas debe ser aprobada por la mayoría de los directores y no pueden votar los directores que forman parte de la sociedad relacionada (Artículo 66 D). Deben también aprobarla la mayoría de los directores independientes. El fundamento es que estos directores independientes y quienes no tienen un interés económico en la celebración del contrato dan garantías de "ecuanimidad" (http://ciperchile.cl del 6 de enero del 2012 y www.cepchile.cl).

¿Da suficientes garantías el proyecto? Parece que no. El valor de mercado del arriendo de un campus universitario siempre será una cuestión debatible. ¿Cuántos campus se ofrecen en arriendo en un momento dado? Hay que tomar en cuenta el número de alumnos, las salas de clases, los patios, las oficinas, laboratorios, biblioteca, baños, en fin.

¿Puede hablarse en este caso de un mercado de arriendos propiamente tal y, por tanto, de un canon de mercado? ¿No ocurrirá, más bien, que muchas veces la universidad estará virtualmente cautiva y en manos de su arrendador? Descartando abusos flagrantes, ¿es realista suponer que los funcionarios de la futura Superintendencia podrían demostrar que la universidad está pagando un arriendo excesivo?

El gerente estará en ventaja desde el punto de vista de la información y será de su interés satisfacer el interés de los controladores. Quedará atrapado en un conflicto de interés: ¿privilegia los intereses de la universidad o los de los controladores de quienes dependen sus bonos, su sueldo, en fin, su puesto?

Luego, ¿qué motivación tendrán los directores independientes para informarse y contradecir la opinión del gerente y la de los socios interesados y controladores de la universidad que - aunque no voten - argumentarán y defenderán sus intereses? Los independientes pueden estar en minoría. Han sido nombrados (y pueden ser removidos) por los controladores, es posible que reciban una dieta y seguramente son amigos... ¿Estarán dispuestos a decir que no? ¿El temor a los controles y sanciones de la Superintendencia será tan grande? No parece probable. "Puede perseguirse la responsabilidad civil de uno de los directores, pero el artículo 66 i establece que queda inhabilitado para hacerlo quien haya concurrido a la aprobación de la operación. ¿No es un incentivo para que los acuerdos se tomen por unanimidad y 
todos los directores queden inhabilitados para perseguir judicialmente la responsabilidad civil?" (Fontaine, 2012).

¿Es práctico poner fin al arriendo? La administración puede tener buenas razones para oponerse. El traslado a un nuevo campus es costoso. El barrio no es indiferente para nadie...

En suma, el proyecto no asegura el cumplimiento de la ley que prohíbe el lucro en las universidades. Por la vía de sociedades relacionadas seguirá ocurriendo lo que ha ocurrido y el mensaje anuncia que se quiere evitar. La dificultad de comprobar el daño a la universidad es lo que aconseja el establecimiento de una norma preventiva.

¿Por qué no prohibir de una buena vez los negocios con sociedades relacionadas y evitar así toda esta alambicada maquinaria de regulación y control? Eso cortaría el problema de raíz. El proyecto debe modificarse e incorporar esa prohibición. La fundamentación es prudencial y preventiva dadas las dificultades que tienen la regulación y el control en esta área. Sería como la norma que prohíbe que un parlamentario sea director de un banco.

¿Cómo transitar gradual y ordenadamente, evitando dañar a los alumnos, desde la anómala situación actual — que se ha hecho manifiestamente insostenible - a una en la que las universidades no puedan contratar con empresas relacionadas? La ley debiera dar un plazo largo para que la universidad compre los bienes raíces que arrienda a empresas relacionadas. Y otorgarle al Estado — quizás a una comisión de especialistas nombrados por diferentes órganos del Estado- facultades para controlar el precio, las condiciones de ese traspaso y monitorear el proceso. En caso extremo debiera ser posible intervenir transitoriamente la universidad. Lo planteo como tema de discusión.

Quisiera dejarlos con una reflexión final.

A veces, las autoridades de los diversos gobiernos de turno se refieren a la universidad en términos que dejan flotando en el aire la sensación de que su misión se reduce a contribuir al crecimiento económico. A veces, uno siente que lo que buscan — quizás desaprensivamente - es conseguir que la universidad sirva a sus planes económicos y políticos. A veces, por la vía oblicua del financiamiento proponen, quizás sin darse mucho cuenta, una universidad sumisa, instrumental, servil, domesticada por los poderosos de la temporada. 
Pero sabemos, como prometió Andrés Bello el día de su fundación, que la libertad "será sin duda el tema de la universidad". No debemos doblegarnos. A nosotros nos toca estar a la altura de esa promesa. Non serviam!

Muchas gracias.

\section{REFERENCIAS}

Acemoglu, Daron y A. Robinson. Why Nations Fail. New York: Crown Business, 2012.

Atria, Fernando. La Mala Educación. Santiago: Catalonia y Ciper, 2012.

Breneman, David. "The University of Phoenix: Icon of For-Profit Higher Education". En David W. Breneman, Brian Pusser y Sarah E. Turner, Earning from Learning. New York: State University of New York, 2006.

Delbanco, Andrew. College: What It Was, Is and Should Be. Princeton and Oxford: Princeton University Press, 2012, location 318.

Deming, David J. Claudia Goldin y Lawrence F. Katz. "The For-Profit PostSecundary School Sector: Nimble Critters or Agile Predators". NBR Working Paper Series 17.710, December, 2011.

Eisman, Steve. Presentación en Ira Sohn Conference, 26 de mayo de 2010. En http://www.marketfolly.com/2010/05/steve-eisman-frontpoint-partnersira.html, Mother Jones y The Huffting Post, 27 de mayo del 2010.

Faust, Drew Gilpin. “The University's Crisis of Purpose”. New York Times, 1 de septiembre de 2009.

Fontaine, Arturo. Presentación ante la Comisión de Educación del Senado sobre el proyecto que crea la Superintendencia de Educación Superior. En http://ciperchile.cl del 6 de enero del 2012 y www.cepchile.cl.

Habermas, Jurgen. Historia y Crítica de la Opinión Pública. Barcelona: Gustavo Gili, 1981 (edición original de 1962).

Kravis, Henry (entrevista). "Cuarto mayor administrador de capital privado evalúa inversión en Chile”. El Mercurio, "Economía y Negocios", el 3 de junio del 2011.

Lang, Kevin y Russell Weinstein. "Evaluating Student Outcomes at For-Profit Colleges", NBR Working Paper Series 18.201, June, 2012.

Marrou, Henri-Irenée. Histoire de L'Education dans l'Antiquité II. Paris: Éditions du Seuil, 1948.

Mönckeberg, María Olivia. El Negocio de las Universidades en Chile. Santiago: Debate, 2012 (primera edición 2007).

Nussbaum, Martha C. Not For Profit. Princeton y Oxford: Princeton University Press, 2010.

Posner, Richard (Becker-Posner Blog). "For-Profit Colleges and UniversitiesPosner's Comment", 22 de enero del 2006, y "For-Profit Colleges and Universities-Posner's Comment”, 22 de enero del 2006. 
Pusser, Brian. "Higher Education, Markets, and the Preservation of the Public Good”. En David W. Breneman, Brian Pusser y Sarah E. Turner, Earnings From Learning. New York: State University of New York Press, 2006.

Putnam, Robert, Robert Leonardi y Raffaella Nanetti: Making Democracy Work: Civic Traditions in Modern Italy. Princeton University Press, 1993.

Qué Pasa. "Universidades: un mercado bullente". Santiago, 18 de junio del 2010.

Ravitch, Diane. The Death and Life of the Great American School System. New York: Basic Books, 2010.

Reuters. "Laurate Education se propone para una TPO”, 29 de marzo de 2012.

Riegg Cellini, Stephanie y Claudia Goldin. "Does Federal Student Aid Raise Tuition? New Evidence on For-Profit Colleges". NBR Working Paper Series 17.827, February, 2012.

Sandel, Michael J. What Money Can't Buy: The Moral Limits of Markets. New York: Farrar, Strauss and Giroux, 2012.

The Economist, 22 de julio del 2010.

Urzúa, Sergio. "La Rentabilidad de la Educación Superior en Chile. Revisión de las Bases de 30 Años de Políticas Públicas". Santiago: Estudios Públicos, $\mathrm{N}^{\mathrm{o}} 125$ (verano, 2012). 